\title{
Randomized Quality Improvement Trial of Opting-In Versus Opting-Out to Increase Influenza Vaccination Rates during Pregnancy
}

\author{
Susan H. Wootton, MD ${ }^{1}$ Sean C. Blackwell, MD ${ }^{2}$ George Saade, MD ${ }^{3}$ Pamela D. Berens, MD ${ }^{2}$ \\ Maria Hutchinson, MS ${ }^{2}$ Charles E. Green, $\mathrm{PhD}^{4}$ Sujatha Sridhar, MBBS, MCE ${ }^{5}$ \\ Kara M. Elam, PhD, MPH, MS ${ }^{4}$ Jon E. Tyson, MD, $\mathrm{MPH}^{4}$
}
${ }^{1}$ Department of Pediatrics, McGovern Medical School at The University of Texas Health Science Center at Houston (UTHealth), Houston, Texas
2 Department of Obstetrics, Gynecology and Reproductive Services, McGovern Medical School at The University of Texas Health Science Center at Houston (UTHealth), Houston, Texas
3 Department of Obstetrics and Gynecology, The University of Texas Medical Branch, Galveston, Texas
${ }^{4}$ Center for Clinical Research and Evidence-Based Medicine, McGovern Medical School at The University of Texas Health Science Center at Houston (UTHealth), Houston, Texas
${ }^{5}$ Research Compliance, Education and Support Services,
The University of Texas Health Science Center at Houston,
Houston, Texas

Am J Perinatol Rep 2018;8:e161-e167.

\begin{abstract}
Address for correspondence Susan H. Wootton, MD, Pediatric Infectious Diseases and Center for Clinical Research and Evidence-Based Medicine, McGovern Medical School at The University of Texas Health Science Center at Houston, 6431 Fannin Street., MSB 2.106, Houston, TX 77030 (e-mail: susan.h.wootton@uth.tmc.edu).
\end{abstract}

\begin{abstract}
Keywords

- pregnancy

- influenza vaccines

- vaccines

- immunization

- consent forms

Introduction Despite strong recommendations, only $40.6 \%$ of pregnant women attending two prenatal clinics were vaccinated against influenza during the 2009 pandemic. We tested whether an opting-out approach would improve vaccine uptake. Methods We conducted a randomized quality improvement (QI) trial to compare opting-out with conventional opting-in consent for influenza immunization. Women age $\geq 18$ years attending the University of Texas Health Science Center at Houston (UTHealth) or UT-Medical Branch (UTMB) prenatal clinics during the 2010-2011 influenza season, were eligible.

Results We enrolled 280 women (140 UTHealth, 140 UTMB). Both groups had similar mean age ( $26.0 \pm 5.5$ years), mean gestational age (19.4 \pm 9.5 weeks), and percent with underlying health conditions (20.7\%). Vaccination rates with opting-in and optingout were similar among all ( 83 vs. $84 \%$ ), UTHealth ( 87 vs. $93 \%$ ), and UTMB patients (79 vs.76\%) $(p>0.05)$. In subsamples of patients assessed, consent strategy did not significantly affect maternal recall of information provided.

Conclusion While prenatal influenza vaccination uptake doubled from the 20092010 influenza season, opting-out did not perform better than opting-in, a conclusion opposite that we would have reached had this been a nonconcurrent trial. Vaccination rates dropped posttrial; hence, continued research is needed to increase the prenatal influenza immunizations.
\end{abstract}

received

January 10, 2018 accepted after revision June 29, 2018
DOI https://doi.org/

10.1055/s-0038-1668566. ISSN 2157-6998.
Copyright $\odot 2018$ by Thieme Medical Publishers, Inc., 333 Seventh Avenue, New York, NY 10001, USA. Tel: +1(212) 584-4662.
License terms

(ㄷ) (i) $\ominus$ (\$) 
Pregnancy increases the risk for serious complications from influenza infection. Despite strong recommendations for universal influenza vaccination of pregnant women, ${ }^{1-4}$ fewer than $55 \%$ of eligible pregnant women in the U.S. are vaccinated. $^{2}$ Women who are uninsured, unemployed, and are of low socioeconomic status have the lowest influenza vaccine rates (14.6-47.2\%), nationally. ${ }^{2}$ Furthermore, only $67.3 \%$ of eligible pregnant women report to have received a recommendation and offer for influenza vaccine. ${ }^{2}$

Vaccination during pregnancy reduces not only preterm delivery among mothers but also influenza, ${ }^{3,5-7}$ treatment with antibiotics, and hospitalizations of their infants. ${ }^{5,8-11}$ Younger infants are particularly at risk as the influenza vaccine is not approved for infants before the age of 6 months. ${ }^{12,13}$ National vaccination rates, during pregnancy, remain far below the $80 \%$ goal of the Healthy People 2020 goal. ${ }^{4,14,15}$ Reasons include failure of obstetricians to provide influenza vaccination in their office, maternal ignorance of the importance of vaccination during pregnancy, and undue maternal concern about vaccine safety. ${ }^{16-18}$

As in other states, written consent for vaccination is not legally required in Texas, only verbal consent. ${ }^{19}$ The usual practice of requiring written consent appears to be an attempt to reduce any litigation risks rather than to meet patients' needs or wants. In our society, written consent is generally required when extra risk, responsibility, liability or cost are incurred. In this context, requiring written consent can be viewed as inherently misleading for immunizations that reduce risk, impose no extra responsibility or liability, and entail minimal cost. ${ }^{20-25}$ The process of requiring a signature to refuse vaccination ("opting-out") may decrease unwarranted fears about vaccine safety and lower refusal rates in comparison to requiring a signature to receive vaccination ("opting-in"). ${ }^{20}$ Opting-out has been found in other circumstances to increase the understanding of information provided in seeking consent, ${ }^{23}$ increased consent rates, and avoid selection biases. ${ }^{26-28}$

In response to consent rates of only 15 to $28 \%$ during the 2009 influenza A(H1N1) pandemic in the U.S., ${ }^{4}$ we conducted a randomized quality improvement (QI) $\operatorname{trial}^{29}$ in 2 centers serving a largely minority population to compare opting-in with opting-out consent for influenza immunization among pregnant women during the 2010-2011 influenza season. We hypothesized that the use of an opting-out approach would increase influenza vaccination rates. We also assessed whether there were major differences in maternal recall of the information provided in seeking consent.

\section{Methods}

\section{Populations}

Women, 18 years old or older, followed up in prenatal clinics of the University of Texas Health Science Center at Houston (UTHealth) or UT-Medical Branch (UTMB) clinics during the October 2010-March 2011 influenza season were eligible for enrollment, irrespective of pregnancy complication. Women with a contraindication to influenza vaccination, a small percentage of our population, were excluded. The majority of the women, served by these clinics have Medicaid or government insurance, are of low socioeconomic status and unemployed. All women services, including obstetrical services, are provided at both sites. Vaccination, delivery at the clinics, is a nurse-driven process. Nurses document maternal vaccination status, obtain written consent, provide a current copy of the Centers for Disease Control and Prevention (CDC) Vaccination Information Statement (VIS) to eligible mothers, prior to vaccination, and administer the vaccine.

\section{Randomization and Consent Procedure for Immunization}

As allowed under federal regulations, ${ }^{30}$ Institutional Review Board (IRB) approval was obtained to waive consent for randomization with the stipulations noted below for this QI trial (\#HSC MS 10-0557). Patients were randomized using consecutively numbered, opaque, sealed envelopes prepared using random.org by project personnel with no patient contact. Randomization occurred at each site. Before approaching the patient, a research nurse (UTHealth) or clinic nurse (UTMB) opened the envelope which contained either an opt-in or an opt-out consent form (see - Appendix A and B). Both forms provide the same written information for the patient to read about influenza infection and vaccination. Each patient was also read a standard script by the nurse based on information taken from the CDC VIS. Patients randomized to the opting-in approach, signed the form if they accepted immunization; those randomized to opt-out, signed the form if they refused vaccination. The nurse recorded whether the vaccine was administered and the reasons stated by any patient who refused the vaccine. At the conclusion of the visit, the nurse read the patient an IRBapproved statement indicating that the patient was enrolled in a randomized trial of consent strategies for immunization.

\section{Assessment of Maternal Recall of Information Provided}

After disclosing randomization, the nurse sought if the patient would be interested in participating in the evaluation described below. As required by our IRB, participating mothers signed a separate consent and Health Insurance Portability and Accountability Act (HIPAA) form. To explore whether there were major differences between groups in recall of the information provided about influenza and vaccination, research nurses at each site, called the first 25 patients who consented. Five attempts ( 2 attempts between 9 a.m. and 5 p. m., 2 attempts between 5 and 9 p.m., and one attempt during the weekend) were made starting 2 days after the clinic visit.

\section{Power and Statistical Analysis}

We retrospectively reviewed vaccination rates for the 20092010 influenza season (the year prior to our trial) to confirm baseline rates. During December 2009, 61.4\% (216 of 352) of eligible pregnant women seen at UTHealth were vaccinated against influenza and $37.4 \%$ (842 of 2,250) women at UTMB clinics; combined $40.6 \%$ (1,058 of 2,602$)$ were vaccinated. To achieve $90 \%$ power to detect an increase to $60 \%$ with an opting-out approach (two-sided $\alpha$ error $=0.05$ ), we calculated that 140 patients would be needed in each group. 
Data were uploaded to an electronic database for analysis (Microsoft Access 2010, Redmond, WA). SAS was used for analysis (SAS version 9.4, Cary, NC). Descriptive characteristics were analyzed using $<\mathrm{i}>\mathrm{C}<|\mathrm{i}\rangle^{2}$ and Fisher's exact. Nonparametric Wilcoxon's tests and median values were used to compare and characterize data failing to meet parametric assumptions; $p$-values $\leq 0.05$ were considered statistically significant. All data were kept in a locked file cabinet and electronic files were password protected. The trial was registered on ClinicalTrials.gov (NCT01233804).

\section{Results}

We enrolled 280 women, 140 from UTHealth and 140 from UTMB. The two consent groups were similar at baseline (see - Table 1). Among all enrollees, mean age was 26.0 years ( \pm 5.5 , range $13.8-42.6)$ and mean gestational age was 19.4

Table 1 Baseline maternal characteristics by consent strategy $(n=280)$

\begin{tabular}{|c|c|c|}
\hline & $\begin{array}{l}\text { Opt-In } \\
(n=140)\end{array}$ & $\begin{array}{l}\text { Opt-Out } \\
(n=140)\end{array}$ \\
\hline $\begin{array}{l}\text { Age, y, mean } \\
\text { (standard deviation } \\
[S D]) \text {, range }\end{array}$ & $\begin{array}{l}26.5(5.5) \\
17.9-42.6\end{array}$ & $\begin{array}{l}25.5(5.4), \\
13.8-42.3\end{array}$ \\
\hline \multirow[t]{2}{*}{$\begin{array}{l}\text { Gestational age, wk, } \\
\text { mean, (SD), range }\end{array}$} & $\begin{array}{l}18.8(9.7) \\
5-40\end{array}$ & $\begin{array}{l}19.9(9.2) \\
4-39\end{array}$ \\
\hline & $n(\%)$ & $n(\%)$ \\
\hline \multicolumn{3}{|l|}{ Ethnicity } \\
\hline Hispanic & $71(50.7)$ & $77(55)$ \\
\hline African American & $52(37.1)$ & $45(32.1)$ \\
\hline Caucasian & $17(12.1)$ & $16(11.4)$ \\
\hline Other ethnicity & 0 & $2(1.4)$ \\
\hline \multicolumn{3}{|l|}{ Trimester $^{\mathrm{a}}$} \\
\hline First & $50(36.0)$ & $37(26.4)$ \\
\hline Second & $47(33.8)$ & $59(42.1)$ \\
\hline Third & $42(30.2)$ & $44(31.4)$ \\
\hline Underlying health conditions ${ }^{b}$ & $29(20.7)$ & $29(20.7)$ \\
\hline Diabetes mellitus & $13(9.3)$ & $6(4.3)$ \\
\hline Asthma & $9(6.4)$ & $11(7.9)$ \\
\hline Hypertension & $9(6.4)$ & $8(5.7)$ \\
\hline Pulmonary & $1(0.7)$ & 0 \\
\hline Cardiac & $1(0.7)$ & $2(1.4)$ \\
\hline Hepatic & $1(0.7)$ & $2(1.4)$ \\
\hline Immunocompromised & 0 & $3(2.1)$ \\
\hline Renal & $0(0.0)$ & 0 \\
\hline \multicolumn{3}{|l|}{ Enrolled $^{c}$} \\
\hline January-March 2011 & $105(75.0)$ & $104(74.8)$ \\
\hline November-December 2010 & $35(25.0)$ & $35(25.2)$ \\
\hline
\end{tabular}

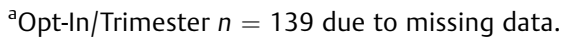

bubcategories can be multiple responses.

'Opt-out/Enrolled $n=139$ due to missing data. weeks ( \pm 9.5 , range $4-40$ ). Most patients were Hispanic ( $n=148$ [52.9\%]); 58 (20.7\%) had underlying conditions. The majority of patients were enrolled during January 1, 2011 to March 30, 2011 (209 [74.6\%]) (late in influenza season).

\section{Vaccination Rates}

The rates were substantially higher among eligible women than expected in both groups, with no significant difference between opting-in and opting-out groups, among all patients (83 [116/140 ] vs. $84 \%[118 / 140], p=0.87$ ) or those at either UTHealth (87 vs. $93 \%, p=0.40$ ) and UTMB (79 vs. $76 \%$, $p=0.84$ ) ( - Fig. 1). A considerable percentage of women in their third trimester (17 [20\%] of 86) and those with underlying conditions ( 7 [12\%] of 58) did not get vaccinated. The most common reason given for refusal was worry about side effects (25 [51\%]). The second was a belief that they were not at risk for influenza (11 [22.4\%]).

\section{Maternal Recall}

Among 51 mothers assessed, 45 (36 vaccinated, 9 unvaccinated) women were reached as 6 did not answer after five attempts. While power was limited, we found no evidence that consent strategy had a large effect on maternal recall of information provided in the consent. Twenty one (88\%) of 24 in the opting-in group versus 20 (95\%) of 21 in the opting-out group ( $p=0.61$ ) could name at least one symptom of influenza. Sixteen (67\%) of 24 in the opting-in group versus 11 (53\%) of 21 in the opting-out group ( $p=0.37$ ) could name one side effect of influenza vaccine.

\section{Discussion}

In this study, we compared two strategies of consenting pregnant women (opting-in vs. opting-out) on influenza vaccination uptake in a parallel, randomized quality improvement trial. The unexpected high vaccination rates in both groups (83-84\%) in our trial is likely due to strong support from departmental leaders at the time (i.e., 1 year after an epidemic season in 2009-2010), monitoring of vaccination rates, and increased attention to the immunization status. A possible second contributing factor could be ethnicity as over half of our patient population was Hispanic (52.9\%). During the 2016-2017 influenza season in the U.S., eligible pregnant women who were Hispanic had the highest rates $(61.2 \%)$ for getting the vaccine when compared with other races and ethnicity. ${ }^{2}$

Note that, the influenza vaccination rates at UTHealth dropped after our trial to $52.9 \%$. Contributing factors to this decline could have been the Hawthorne effect, when individuals modify or improve an aspect of their behavior in response to their awareness of being observed. ${ }^{31}$ Additionally, the intense media coverage of the 2009-2010 influenza season, which contributed to a heightened perception of risk among communities and increased in proactive measures, such as getting an influenza vaccination, waned. ${ }^{32,33}$ Similar to our trial results, national influenza vaccination rates also dropped in the U.S. after the 2009-2010 influenza season. 34,35 


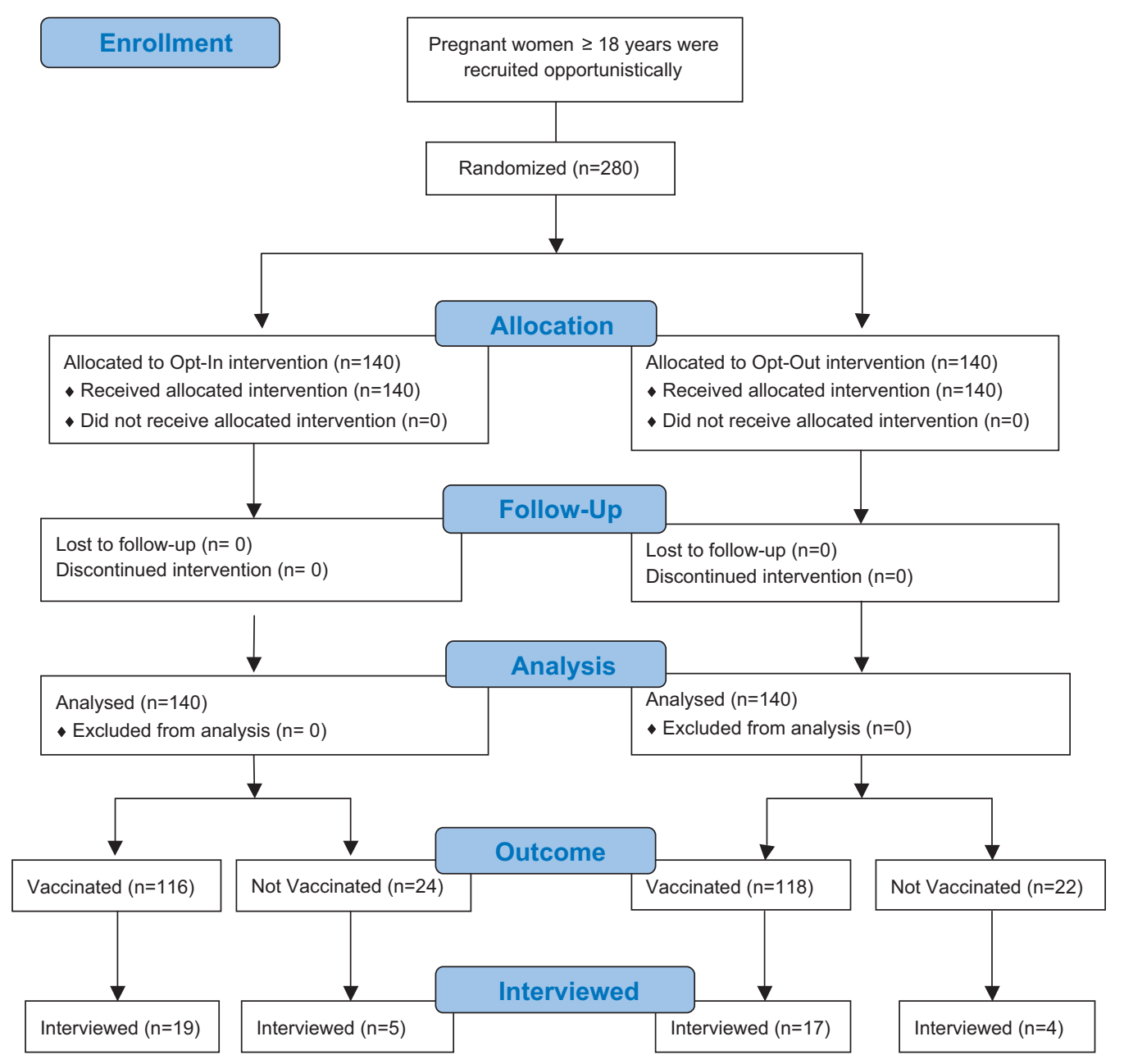

Fig. 1 Flow diagram of progress through phases of trial.

This study has important implications for clinicians. First, even our relatively high rates, left a sizable percentage of women at risk, particularly among those with underlying conditions. One fifth $(20 \%)$ of women in their third trimester and one in tenth (12\%) with underlying conditions did not get vaccinated. Such patients are at particularly increased risk of influenza morbidity and should be specifically targeted for vaccination. ${ }^{3,36}$ To date, a healthcare provider recommendation remains one of the strongest predictors of influenza vaccination among women. ${ }^{37}$

Our findings are also relevant for policy makers, who involved in clinical research, such as IRB members. Optingout strategies improve recruitment, reduce selection bias, and increase patient understanding, recall, and satisfaction in clinical research that involves minimal risk. ${ }^{23,28}$ This approach however remains controversial, as IRB generally require conventional opting-in consent for participants in research. For studies; however, where risks from research are not increased or even reduced, such as minimal-risk comparative effectiveness or quality improvement trials, an opting-out consent strategy is increasingly seen as acceptable. $^{27,38-43}$ Additionally, our trial design, which included randomization, avoided common biases associated with typical observation QI studies. ${ }^{44}$ In particular, a pre-post design would have erroneously concluded that our intervention had an effect. ${ }^{45}$

Despite continued suboptimal maternal vaccination rates in the U.S. (37.4\% during 2016-2017), ${ }^{2}$ few interventions to increase maternal agreement to influenza vaccination have been well tested. ${ }^{46-48}$ An important strength of this trial, is that it was an innovative strategy, utilizing and assessing the role of consent, on influenza vaccine uptake rates among pregnant women. Opt-out consents are already used in clinical practice and have led to clear improvements in healthcare and immunization rates in nonpregnant persons. ${ }^{20,21,25}$ Creative strategies addressing patient and healthcare provider barriers to vaccination, such as why obstetricians do not routinely recommend vaccination during pregnancy, are needed especially in states such as Texas where maternal mortality continues to rise. ${ }^{49-52}$

Our trial had several limitations. First, only 2 centers were included. Both were academic centers and both offered vaccinations on site which could limit the generalizability of our findings to other centers. Second, the majority of our patients were enrolled during the second half of influenza season (January to March, 2011) which could have increased the number of opportunities for women to have been vaccinated. Finally, we attempted to standardize vaccination 
information presented to patients in both groups by using a script. Again, this strategy could have impacted vaccination rates as compared with usual practice.

\section{Conclusion}

Our trial serves as a unique example of a randomized QI trial to test a strategy to augment the delivery of a proven medical intervention. Our data indicate that with undue effort to optimize influenza immunization rates during pregnancy, rates exceeding $80 \%$ can be achieved, even in populations that tend to have low immunization rates. Unfortunately, a sizable proportion of high-risk patients continued to decline vaccination, and most women who declined vaccination were unduly afraid of side effects. With this relatively high rate of immunization, the use of opting-out did not increase immunizations over that with opting-in. However, as for immunization, as for other procedures or therapies, the use of opting-out might help to increase immunizations in settings with low rates that are associated with conventional opting-in approaches. Continued research is needed to identify and implement methods to increase influenza immunizations during pregnancy. ${ }^{51,53}$

\section{Conflict of Interest}

The authors report no conflict of interest.

\section{Funding Source}

All phases of this trial were supported by a KL2 CCTS Supplement Award \#3KL2RR024149-05S1, a CTSA Award \#UL1RR024148 and the Larry C. Gilstrap Center for Perinatal and Women's Health Research, University of Texas Health Science Center at Houston, Houston, TX.

\section{References}

1 Committee on Obstetric Practice and Immunization Expert Work Group; Centers for Disease Control and Prevention's Advisory Committee on Immunization, United States; American College of Obstetricians and Gynecologists. Committee opinion no. 608: influenza vaccination during pregnancy. Obstet Gynecol 2014; 124(03):648-651

2 Ding $\mathrm{H}$, Black $\mathrm{CL}$, Ball $\mathrm{S}$, et al. Influenza vaccination coverage among pregnant women-United States, 2016-17 influenza season. MMWR Morb Mortal Wkly Rep 2017;66(38):1016-1022

3 Harris JW. Influenza occurring in pregnant women: a statistical study of thirteen hundred and fifty cases. JAMA 1919;72(14): 978-980

4 Henninger M, Crane B, Naleway A. Trends in influenza vaccine coverage in pregnant women, 2008 to 2012. Perm J 2013;17(02): 31-36

5 Rasmussen SA, Jamieson DJ. Influenza and pregnancy in the United States: before, during, and after 2009 H1N1. Clin Obstet Gynecol 2012;55(02):487-497

6 Richards JL, Hansen C, Bredfeldt C, et al. Neonatal outcomes after antenatal influenza immunization during the 2009 H1N1 influenza pandemic: impact on preterm birth, birth weight, and small for gestational age birth. Clin Infect Dis 2013;56(09):1216-1222

7 Zaman K, Roy E, Arifeen SE, et al. Effectiveness of maternal influenza immunization in mothers and infants. N Engl J Med 2008;359(15):1555-1564
8 Benowitz I, Esposito DB, Gracey KD, Shapiro ED, Vázquez M. Influenza vaccine given to pregnant women reduces hospitalization due to influenza in their infants. Clin Infect Dis 2010;51(12): 1355-1361

9 Eick AA, Uyeki TM, Klimov A, et al. Maternal influenza vaccination and effect on influenza virus infection in young infants. Arch Pediatr Adolesc Med 2011;165(02):104-111

10 Maltezou HC, Fotiou A, Antonakopoulos N, et al. Impact of postpartum influenza vaccination of mothers and household contacts in preventing febrile episodes, influenza-like illness, healthcare seeking, and administration of antibiotics in young infants during the 2012-2013 influenza season. Clin Infect Dis 2013;57(11):1520-1526

11 Poehling KA, Szilagyi PG, Staat MA, et al; New Vaccine Surveillance Network. Impact of maternal immunization on influenza hospitalizations in infants. Am J Obstet Gynecol 2011;204(06, Suppl 1):S141-S148

12 Gill PJ, Ashdown HF, Wang K, et al. Identification of children at risk of influenza-related complications in primary and ambulatory care: a systematic review and meta-analysis. Lancet Respir Med 2015;3(02):139-149

13 Yen CJ, Louie JK, Schechter R. Infants hospitalized in intensive care units with 2009 H1N1 influenza infection, California, 2009-2010. Pediatr Infect Dis J 2012;31(03):e52-e55

14 Kennedy ED, Ahluwalia IB, Ding H, Lu P-J, Singleton JA, Bridges CB. Monitoring seasonal influenza vaccination coverage among pregnant women in the United States. Am J Obstet Gynecol 2012;207 (3, Suppl):S9-S16

15 Department of Health and Human Services (U.S.). Healthy People 2020: Immunization and infectious diseases [cited March 9, 2016]. Available at: https://www.healthypeople.gov/2020/topics-objectives/topic/immunization-and-infectious-diseases

16 Rossmann Beel E, Rench MA, Montesinos DP, Healy CM. Acceptability of immunization in adult contacts of infants: possibility of expanding platforms to increase adult vaccine uptake. Vaccine 2014;32(22):2540-2545

17 Beel ER, Rench MA, Montesinos DP, Mayes B, Healy CM. Knowledge and attitudes of postpartum women toward immunization during pregnancy and the peripartum period. Hum Vaccin Immunother 2013;9(09):1926-1931

18 MacDonald NE, Riley LE, Steinhoff MC. Influenza immunization in pregnancy. Obstet Gynecol 2009;114(2 Pt 1):365-368

19 Texas Civil Practice and Remedies Code ( $\$ \S 74.102-103)$. Available at: https://statutes.capitol.texas.gov/Docs/CP/htm/CP.74.htm. Accessed May 22, 2018

20 Chapman GB, Li M, Colby H, Yoon H. Opting in vs opting out of influenza vaccination. JAMA 2010;304(01):43-44

21 Halpern SD, Ubel PA, Asch DA. Harnessing the power of default options to improve health care. N Engl J Med 2007;357: $1340-1344$

22 Johnson EJ, Goldstein D. Do defaults save lives? Science 2003;302 (5649):1338-1339

23 Rogers CG, Tyson JE, Kennedy KA, Broyles RS, Hickman JF. Conventional consent with opting in versus simplified consent with opting out: an exploratory trial for studies that do not increase patient risk. J Pediatr 1998;132(04):606-611

24 Choi JJ, Laibson D, Madrian BC, Metrick A. Optimal defaults. Am Econ Rev 2003;93(02):180-185

25 Ribner BS, Hall C, Steinberg JP, et al. Use of a mandatory declination form in a program for influenza vaccination of healthcare workers. Infect Control Hosp Epidemiol 2008;29(04):302-308

26 Berry JG, Ryan P, Gold MS, Braunack-Mayer AJ, Duszynski KM; Vaccine Assessment Using Linked Data (VALiD) Working Group. A randomised controlled trial to compare opt-in and opt-out parental consent for childhood vaccine safety surveillance using data linkage. J Med Ethics 2012;38(10):619-625

27 Junghans C, Feder G, Hemingway H, Timmis A, Jones M. Recruiting patients to medical research: double blind randomised trial of “opt-in" versus “opt-out” strategies. BMJ 2005;331(7522):940 
28 Treweek S, Mitchell E, Pitkethly M, et al. Strategies to improve recruitment to randomised controlled trials. Cochrane Database Syst Rev 2010;14(04):MR000013

29 Fan E, Laupacis A, Pronovost PJ, Guyatt GH, Needham DM. How to use an article about quality improvement. JAMA 2010;304(20): 2279-2287

30 Code of Federal Regulations. Title 45: Public Welfare. U.S. Department of Health and Human Services. Part 46, Protection of Human Subjects. Available at: https://www.hhs.gov/ohrp/sites/default/ files/ohrp/policy/ohrpregulations.pdf 2009

31 McCambridge J, Witton J, Elbourne DR. Systematic review of the Hawthorne effect: new concepts are needed to study research participation effects. J Clin Epidemiol 2014;67(03):267-277

32 Collinson S, Khan K, Heffernan JM. The effects of media reports on disease spread and important public health measurements. PLoS One 2015;10(11):e0141423

33 McCluskey J, Swinnen J. The media and food-risk perceptions. EMBO Rep 2011;12(07):624-629

34 Borse RH, Shrestha SS, Fiore AE, et al. Effects of vaccine program against pandemic influenza $A(H 1 N 1)$ virus, United States, 20092010. Emerg Infect Dis 2013;19(03):439-448

35 Chiu APY, Dushoff J, Yu D, He D. Patterns of influenza vaccination coverage in the United States from 2009 to 2015. Int J Infect Dis 2017;65:122-127

36 Neuzil KM, Reed GW, Mitchel EF, Simonsen L, Griffin MR. Impact of influenza on acute cardiopulmonary hospitalizations in pregnant women. Am J Epidemiol 1998;148(11):1094-1102

37 Ault KA, Heine RP, Riley LE. Programmatic and research priorities for improving influenza immunization of pregnant women. Am J Obstet Gynecol 2012;207(3, Suppl):S75-S77

38 Chu HY, Englund JA. Maternal immunization. Clin Infect Dis 2014; 59(04):560-568

39 Mutch L, King R. Obtaining parental consent-opting in or opting out? Arch Dis Child 1985;60(10):979-980

40 Trevena L, Irwig L, Barratt A. Impact of privacy legislation on the number and characteristics of people who are recruited for research: a randomised controlled trial. J Med Ethics 2006;32(08):473-477

41 Whicher D, Kass N, Faden R. Stakeholders' views of alternatives to prospective informed consent for minimal-risk pragmatic comparative effectiveness trials. J Law Med Ethics 2015;43(02):397-409
42 Matjasko JL, Cawley JH, Baker-Goering MM, Yokum DV. Applying behavioral economics to public health policy: illustrative examples and promising directions. Am J Prev Med 2016;50(05, Suppl 1):S13-S19

43 Yeung K. The forms and limits of choice architecture as a tool of government. Law Policy 2016;38(03):186-210

44 Howell V, Schwartz AE, O'Leary JD, Mc Donnell C. The effect of the SQUIRE (Standards of QUality Improvement Reporting Excellence) guidelines on reporting standards in the quality improvement literature: a before-and-after study. BMJ Qual Saf 2015;24 (06):400-406

45 Mueck KM, Putnam LR, Kao LS. Improving the quality of quality improvement reporting: standards for quality improvement reporting excellence (squire) 2.0 guidelines. JAMA Surg 2016; 151(04):311-312

46 Meharry PM, Cusson RM, Stiller R, Vázquez M. Maternal influenza vaccination: evaluation of a patient-centered pamphlet designed to increase uptake in pregnancy. Matern Child Health J 2014;18 (05):1205-1214

47 Moniz MH, Hasley S, Meyn LA, Beigi RH. Improving influenza vaccination rates in pregnancy through text messaging: a randomized controlled trial. Obstet Gynecol 2013;121(04):734-740

48 Yudin MH, Salripour M, Sgro MD. Impact of patient education on knowledge of influenza and vaccine recommendations among pregnant women. J Obstet Gynaecol Can 2010;32(03):232-237

49 Baeva S, Saxton DL, Ruggiero K, et al. Identifying maternal deaths in Texas using an enhanced method, 2012. Obstet Gynecol 2018; 131(05):762-769

50 MacDorman MF, Declercq E, Thoma ME. Making vital statistics count: preventing U.S. maternal deaths requires better data. Obstet Gynecol 2018;131(05):759-761

51 Shavell VI, Moniz MH, Gonik B, Beigi RH. Influenza immunization in pregnancy: overcoming patient and health care provider barriers. Am J Obstet Gynecol 2012;207(3, Suppl):S67-S74

52 Centers for Disease Control and Prevention. Pregnant women and flu vaccination, internet panel survey, United States. November 2017. Available at: https://www.cdc.gov/flu/fluvaxview/pregnantwomen-nov2017.htm

53 Rasmussen SA, Jamieson DJ. 2009 H1N1 influenza and pregnancy-5 years later. N Engl J Med 2014;371(15):1373-1375 


\section{Appendix A Opt-In Consent (version 1.0)}

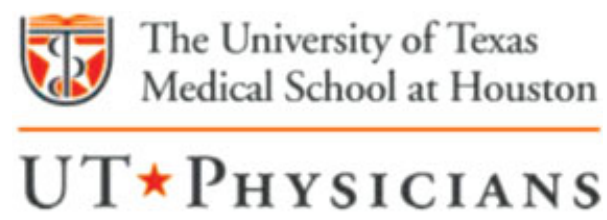

\section{Influenza Virus Vaccine}

Please read this carefully

All people, age 6 months or older, are recommended to receive annual influenza vaccine. Pregnant women are at risk for serious complications of influenza infection. Women who are pregnant during the influenza season are recommended to receive influenza vaccine.

I have read the Vaccine Information Statement about influenza vaccine. I have had a chance to ask questions which were answered to my satisfaction. I believe I understand the benefits and risks.

I agree to receive the influenza vaccine today.

Patient (print):

Patient (signature):

Date $(\mathrm{mm} / \mathrm{dd} / \mathrm{yy})$ : Time:

Witness (print):

Witness (signature):

Date $(\mathrm{mm} / \mathrm{dd} / \mathrm{yy})$ : Time:

\section{Appendix B Opt-Out Consent (version 1.0)}

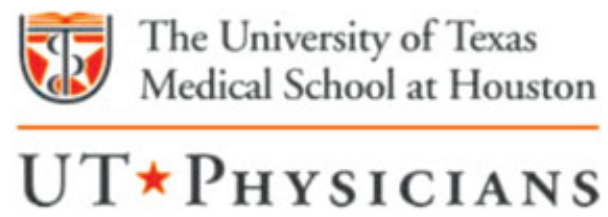

Please read this carefully

I understand that my healthcare provider has recommended that I receive the influenza vaccine.

I have read the Vaccine Information Statement about the influenza vaccine and the disease it prevents. I have had a chance to discuss this with my healthcare provider who has answered all of my questions about the influenza vaccine.

I understand that the American Academy of Pediatrics, the Centers for Disease Control and Prevention, the American College of Obstetrics and Gynecology, and the Advisory Committee on Immunization Practices have all recommended that I receive the influenza vaccine.

Nevertheless, I have decided to decline the influenza vaccination.

I know that failure to follow the recommendations about vaccination may endanger my health or life and others with whom I have contact.

I know that I may readdress this issue with my healthcare provider at any time and that I may change my mind and accept the influenza vaccination in the future.

I acknowledge that I have read this document in its entirety and fully understand it.

Signature: Date:

Witness: Date: 